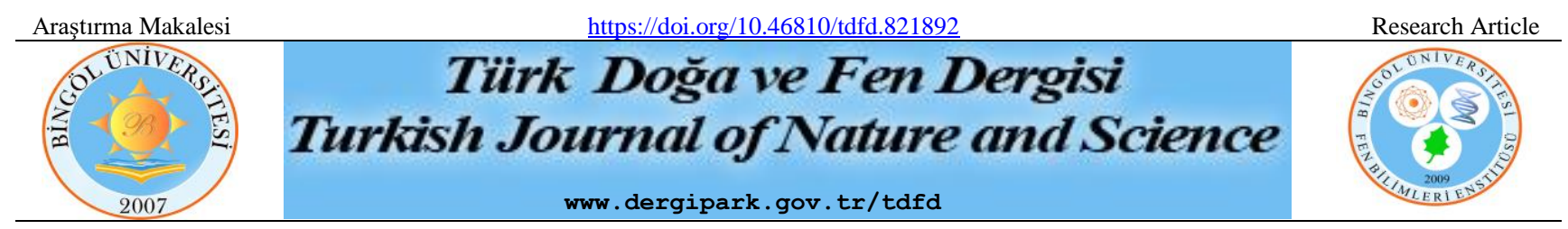

\title{
Aspir Genotiplerinde Çiçek Verimi ile Bazı Morfolojik Özellikler Arasındaki İlişkilerin Belirlenmesi
}

\author{
Hasan KOÇ ${ }^{1 *}$, Ahmet GÜNEŞ ${ }^{1}$ \\ ${ }^{1}$ Bahri Dağdaş Uluslararası Tarımsal Araştırma Enstitüsü, Konya, Türkiye \\ Hasan KOÇ ORCID No: 0000-0003-1728-070X \\ Ahmet GÜNEŞ ORCID No: 0000-0003-4205-5037
}

*Sorumlu yazar: koc175@hotmail.com

(Alınış: 05.11.2020, Kabul: 17.03.2021, Online Yayınlanma: 25.06.2021)

Anahtar
Kelimeler
Aspir,
Biplot,
Çiçek,
Tabla

\section{Determining the Relationships between Flower Yield and Some Morphological Traits in Safflower Genotypes}

Öz: Bu çalışma, 20 aspir genotipi ile 2020 yılında Konya Bahri Dağdaş Uluslararası Tarımsal Araştırma Enstitüsü'nde yürütülmüştür. Deneme, Tesadüf Blokları Deneme Desenine göre dört tekerrürlü olarak kurulmuştur. Araştırma ile aspir ıslah çalışmaları kapsamında geliştirilen aspir hatları ve bazı tescilli çeşitlerin (Koç, Linas, Balcı, Dinçer, Göktürk) çiçek verimlerinin tespit edilmesi ve çiçek veriminin bazı morfolojik özelliklerle olan ilişkilerinin belirlenmesi amaçlanmıştır. Genotiplerin ortalama çiçek verimi değerleri 8,5 ile 24,0 kg/da arasında değişmiştir. Hatlardan en yüksek çiçek verimi 24,0 kg/da ile G1'den elde edilirken bunu 20,7 kg/da ile G2 ve 20 $\mathrm{kg} / \mathrm{da}$ ile G3 takip etmiştir. Tescilli çeşitler ise çiçek verimi açısından yüksekten düşüğe doğru, Göktürk (22,2 kg/da), Linas (21,5 kg/da), Dinçer (18,7 kg/da), Balcı (13,5 kg/da), Koç (11,5 kg/da) şeklinde sıralanmıştır. Deneme ortalaması ise $17,1 \mathrm{~kg} / \mathrm{da}$ olmuştur. Genotipler arasında çiçek verimi bakımından önemli varyasyon tespit edilmiştir. Çalışmada çiçek verimi ile bazı morfolojik özellikler arasındaki ilişkiler hem korelasyon analizi hem de biplot analizi ile ortaya konmuştur. Araştırma sonucunda her iki analize göre de aspirde çiçek verimi ile tabla sayısı ve yan dal sayısı arasında önemli ve pozitif ilişki tespit edilmiştir.
Keywords

Safflower.

Biplot,

Flower,

Capitula

\begin{abstract}
This study was conducted in Konya Bahri Dagdas International Agricultural Research Institute in 2020 with 20 safflower genotypes. The experiment was carried out in four replications according to the randomized blocks trial design. With the research, it was aimed to determine the flower yields of safflower lines and some registered varieties (Koç, Linas, Balcı, Dinçer and Göktürk) developed within the scope of safflower breeding studies and to determine the relationship between flower yield and some morphological characteristics. The highest flower yield of the lines was obtained from G1 with 24,0 kg da-1, followed by G2 with 20,7 kg da-1 and G3 with 20,0 kg da-1. Registered varieties are from high to low in terms of flower yield, Göktürk (22,2 kg da-1), Linas (21,5 kg da-1), Dinçer (18,7 kg da-1), Balcı (13,5 kg da-1/), Koç (11,5 kg da-1) lined up. The average of the experiment was $17,1 \mathrm{~kg}$ da-1. Significant variations were found among genotypes in terms of flower yield. The study revealed the relationships between flower yield and some morphological characteristics by both correlation analysis and biplot analysis. As a result of the research, a significant and positive relationships were found between safflower flower yield and the number of head and the number of side branches according to both analyzes.
\end{abstract}

\section{GíRiş}

İnsanlar tarafından 2200 yıldan fazla bir süredir aspir bitkisi çeşitli amaçlar için kullanılmaktadır [1]. Aspir çiçekleri geleneksel olarak, gıda ve tekstil ürünlerini renklendirmek için kullanılmıştır [2]. Bununla birlikte, 1856 'da daha ucuz, sentetik boyalar icat edildiğinde bu geleneksel kullanım arka plana çekilmiştir [3].

Aspirin şu anda en büyük kullanım alanı, yağ bileşimi ve ayçiçek yağına sağlıklı bir alternatif olarak kabul 
edilmesi nedeniyle yemeklik yağ olarak kullanılmasıdır [4]. Yağ1 yanında sebze, hayvan yemi, çay, kesme çiçek veya tıbbi bitki gibi birçok kullanımı vardır [5]. Aspir, çiçeklerinde bulunan renk pigmentleri Carthamidin (sarı renk) ve Carthamin (kırmızı renk) sayesinde önemli bir boya bitkisidir [6].

Aspir bitkisinin her birinin beyaz, sarı, turuncu veya kırmızı çiçekler içeren küresel tablaları vardır [1,7]. Bu tablalarda ortalama yüze yakın çiçek oluşmakla birlikte, bu çiçeklerin ancak ortalama \%20'si tohum oluşturmaktadır [8].

Uluslararası düzeyde, aspirin çiçeği için yetiştiriciliği şu anda sinırlıdır ve hala esas olarak Asya'da yapılmaktadır [2,9]. Ancak bu, özellikle Avrupa ve diğer Batı ülkelerinde gida boyası endüstrisinin artan talebini karşılamak için artık yeterli olmayacaktır [10]. Bunun için Türkiye gibi önemli ekim alanına sahip ülkelerde aspir çiçeğinin boya endüstrisinde kullanım olanakları araştırılmalıdır.

Son yıllarda yapılan çalışmalarda, yapay gıda boyalarının çocukların sağlıklarını olumsuz etkilediği, kanserojen veya alerjik etkilere neden olabileceği iddia edilmektedir [11,12]. Çevreye duyarlı, güvenli ve sağlıklı tüketim konusunda artan farkındalık nedeniyle doğal renklendiricilere olan ilgi artmıştır [13].

Aspir çiçeklerinde bulunan pigmentler, diğer renklendiricilere kıyasla özellikle 1 şık, sıcaklık ve $\mathrm{pH}$ değeri ile ilgili özelliklerde birtakım avantajlara sahiptir ve safrandan daha ucuzdur [14,15].

Çiçek üretimi için aspir çoğunlukla elle hasat edilir. Bu ise, çok yavaş, emek ve zaman gerektiren aynı zamanda pahalı bir işlemdir $[16,17]$.

Günümüze kadar aspir çiçeğinin hasat edilerek kullanımı için endüstriyel olarak geliştirilmiş bir hasat makinesi bulunmaması nedeniyle büyük ölçekli çiçek üretimi mümkün olmamıştır [18]. Bu nedenle, hasadın mekanizasyonu için uygun bir yöntem geliştirilmeli ve test edilmelidir.

Almanya'da, Hohenheim Üniversitesinde 2017-2018 yıllarında aspir çiçeğinin kullanımı için hasadın mekanizasyonu çalışmaları yapılmıştır. $\mathrm{Bu}$ amaçla biçerdöverde çeșitli uyarlamalar yapılarak harmanlama verimliliğine uygun hale getirilmiştir [19]. Biçerdöver ile çiçeklerin hasat edilmesinin el hasadına kıyasla maliyeti düşüreceği böylece, gelecekte Almanya'daki gıda boyası endüstrisi için aspir yetiștiriciliğinin daha çekici hale geleceği bildirilmiştir [9]. Güneybatı Almanya'da boya endüstrisinde kullanılmak amacıyla aspir çiçeği elde etmek için çalışmalar yapılmış, bu çalışmalar çiçek veriminin, renklendirici içeriği ve renklendirici veriminin diğer uluslararası çalışmalarla rekabet edebileceğini göstermiştir. $\mathrm{Bu}$ araştırmalar özellikle Avrupa ülkelerinin doğal gıda boyası endüstrisinde kullanmak amaciyla aspir bitkisiyle yakından ilgilendiklerini göstermektedir.
Türkiye'de 2020 yılı istatistiklerine göre 151000 da alanda aspir ekimi yapilmakta ve aspirin yalnızca tohumundan faydalanılmaktadır [20]. Aspir tohumu ve yağı ile ilgili araştırmalar oldukça fazla olmakla birlikte; diğer kullanım amaçlarına yönelik (çiçek, boya, tıbbi vb.) çalışmalar oldukça sınırlıdır. Bu çalışmada, "Orta Anadolu Bölgesi Aspir Islah Çalışmaları" kapsamında geliştirilen aspir hatları ve bazı tescilli çeşitlerin çiçek verimlerinin tespit edilmesi ve çiçek veriminin bazı morfolojik özelliklerle olan ilișkilerinin belirlenmesi amaçlanmıştır.

\section{MATERYAL VE METOT}

$\mathrm{Bu}$ araştırma, aspir 1slah çalışmaları kapsamında, seleksiyon çalışmaları ile geliştirilen 15 genotip ve 5 tescilli çeşit (Koç, Göktürk, Dinçer, Balcı, Linas) ile 2020 yılında Bahri Dağdaş Uluslararası Tarımsal Araştırma Enstitüsü deneme arazisinde yürütülmüştür. Denemeler, Tesadüf Blokları deneme desenine göre dört tekerrürlü olarak kurulmuştur. Deneme parselleri 1,2 m eninde, $5 \mathrm{~m}$ uzunluğunda düzenlenmiş ve parsel alanı 6,0 $\mathrm{m} 2$ olacak şekilde deneme mibzeri ile ekim yapılmıştır. Ekim, 30 Mart 2020 tarihinde yapılmıştır. Sıra arası 20 $\mathrm{cm}$ ve 125 adet $/ \mathrm{m} 2$ ekim sıklığ1 olacak şekilde yapılmıştır. Hasat, 18 Ağustos tarihinde parsel alanının tamamında $(6,0 \mathrm{~m} 2)$ parsel biçerdöveriyle yapılmıştır.

Denemenin yürütüldüğü yıla (2020) ait vejetasyon devresi yağış miktarı ve sıcaklık değerleri Tablo1'de verilmiştir. 2020 y1lı vejetasyon devresi ortalama sıcaklıklar uzun yıllar ortalamasına yakın gerçekleşirken, aynı dönemdeki yağış toplamı ise uzun yıllar ortalamasının oldukça altında gerçekleşmiștir (Tablo 1). Deneme yeri toprakları; killi-tınlı bir bünyeye sahiptir. Organik madde içeriği orta seviyededir (\%2,3). Toprağın kireç miktarı \%29 olup yüksektir. Asitlik derecesi (pH 7,8) hafif alkali sinıfa girmektedir. Fosfor ve potasyum miktarı bakımından zengindir. Tuzluluk sorunu bulunmamaktadır.

Tablo 1. Denemenin yürütüldüğü yıla (2020) ve uzun yillara (19292020) ait vejetasyon devresindeki aylık yağış miktarı(mm) ve aylık sicaklık ortalamaları $(\mathrm{C} 0)$

AYLAR

\begin{tabular}{|c|c|c|c|c|c|c|c|c|}
\hline & Yil & 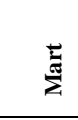 & 蛋 & $\sum_{\bar{\pi}}^{n}$ & $\underset{\mathbb{Z}}{\mathbb{\Xi}}$ & $\underset{\mathrm{E}}{\stackrel{\mathrm{E}}{\mathrm{U}}}$ & 苍 & $\frac{\tilde{E}}{\stackrel{\Xi}{\varrho}}$ \\
\hline \multirow[t]{2}{*}{ Yağıș } & 2020 & 6,4 & 3,4 & 23,4 & 35,8 & 0,6 & 12,8 & 82,4 \\
\hline & Uz. Yil. & 26,2 & 38,8 & 41,7 & 20,1 & 7,5 & 5 & 139.3 \\
\hline \multirow[t]{2}{*}{ Sicaklık } & $\begin{array}{l}2020 \\
\text { Uz. }\end{array}$ & 6,5 & 12,0 & 16,1 & 20,2 & 25,5 & 23,7 & $\begin{array}{l}\text { Ort. } \\
17,3\end{array}$ \\
\hline & Yıl. & 5,7 & 11 & 15,8 & 20,4 & 23,6 & 23,2 & 16,6 \\
\hline
\end{tabular}

Araştırmada; çiçek verimi ile tabla çapı, tabla sayısı, yan dal sayısı, bitki boyu ölçümleri yapılmıştır. Çiçekler hasattan bir gün önce 17 Ağustos tarihinde elle toplanmış olup, 72 saat süre ile $80{ }^{\circ} \mathrm{C}$ ' de kurutularak tartılmıştır. Elle ve makineli hasatta elde edilen çiçeklerin farkını ortaya koymak için; bu çalışmada elle toplanan çiçekler (Şekil 1) ve Steberl ve ark. [9] 
tarafından makine ile hasat edilip sonra harmanlanan çiçeklere ait resimler ise Şekil 2 de verilmiştir.

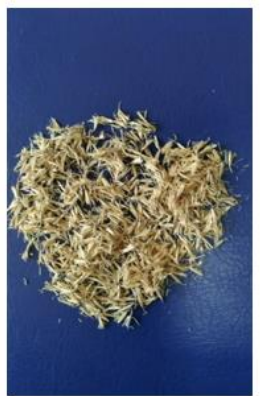

(a)

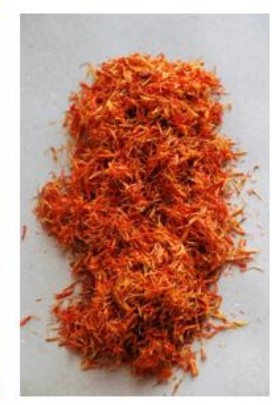

(b)

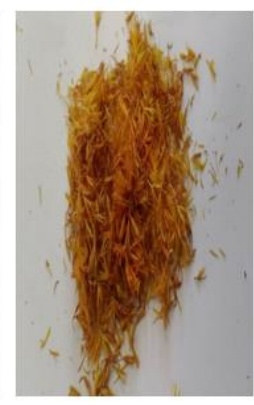

(c)
Şekil 1. Elle hasat edilen (a) beyaz, (b) turuncu, (c) sarı aspir çiçeği

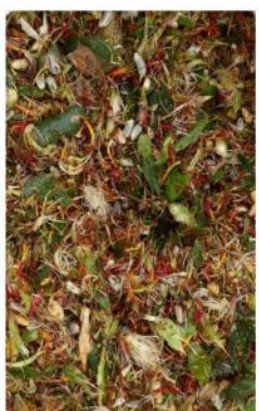

(a)

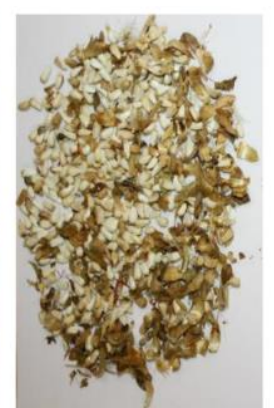

(b)

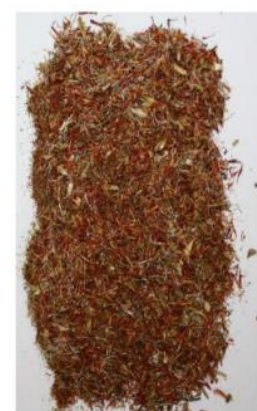

(c)
Şekil 2. Makine ile hasat edilip sonra harmanlanan çiçeklere ait resimler (a) Hasattan hemen sonra harmanlanmamış numunenin fotoğrafları, (b) elekten geçirildikten sonra elekte kalan kalıntı, (c) elenmeden sonra elde edilen çiçek kısmı (Steberl ve ark.[9] .

Elde edilen veriler, JMP 5.0 yazılımı yardımıyla varyans ve korelasyon analizine tabi tutulmuştur. LSD testi yardımıyla önemli ortalamalar karşılaştırılmıştır. Genotip - Özellik ve özellikler arasındaki ilişkilerinin görsel değerlendirilmesi için GT biplot analizi GENSTAT yazılımı kullanılarak yapılmıştır.

\section{BULGULAR VE TARTIŞMA}

Varyans analiz tablosuna göre incelenen tüm özellikler yönünden genotipler arasındaki fark \%1 önem seviyesinde önemli bulunmuştur (Tablo 2).
Tablo 2. Araştırmada incelenen özelliklere ait varyans analizi

\begin{tabular}{|c|c|c|c|c|c|c|}
\hline \multirow{2}{*}{$\begin{array}{l}\text { Varyasyon } \\
\text { Kaynağı }\end{array}$} & \multirow{2}{*}{ 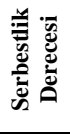 } & ÇV & TC & TS & YDS & BB \\
\hline & & $\mathrm{KO}$ & $\mathrm{KO}$ & $\mathrm{KO}$ & KO & KO \\
\hline Bloklar & 3 & 15.6 & 0,002 & 0,4 & 0,15 & $56,0 * *$ \\
\hline Genotipler & 19 & $61,7 * *$ & $0,067 * *$ & $33,2 * *$ & $19,4 * *$ & $69,4^{* *}$ \\
\hline Hata & 57 & 11,2 & 0,005 & 4,2 & 1,6 & 10,9 \\
\hline Toplam & 79 & $23,5^{* *}$ & $0,02 * *$ & $11,0 * *$ & $5,8 * *$ & $26,7 * *$ \\
\hline
\end{tabular}

Ortalama çiçek verimi değerleri 8,5 ile $24,0 \mathrm{~kg} / \mathrm{da}$ arasında değişmiştir (Tablo 3). Hatlarda en yüksek çiçek verimi $24,0 \mathrm{~kg} / \mathrm{da}$ ile $\mathrm{G} 1$ ' den elde edilirken bunu 20,7 $\mathrm{kg} / \mathrm{da}$ ile $\mathrm{G} 2$ ve $20,0 \mathrm{~kg} / \mathrm{da}$ ile G3 ve G4 takip etmiştir. Tescilli çeşitler ise çiçek verimi açısından yüksekten düşüğe doğru, Göktürk (22,2 kg/da), Linas $(21,5 \mathrm{~kg} / \mathrm{da})$, Dinçer (18,7 kg/da), Balcı (13,5 kg/da), Koç (11,5 kg/da) şeklinde sıralanmıştır. Deneme ortalaması ise $17,1 \mathrm{~kg} / \mathrm{da}$ olmuştur. Çiçek rengi açısından sarı-turuncu çiçek rengine sahip (sarı açıp turuncuya dönen) genotipler genel olarak yüksek çiçek verimi vermiştir.

Aspir genotipleri ile yapılan çalışmalarda çiçek verimini; Köse ve Bilir [21] 3,5 $\quad-11,2 \quad \mathrm{~kg} / \mathrm{da}$ arasında bulmuşlardır. Buna karşılık Süer [22] 11,18-21,48 kg/da; Uysal ve ark. [23] 2,5-8,0 kg/da; Kırıc1 ve İnan [24] 9,3$12,6 \mathrm{~kg} / \mathrm{da}$ arasında değiştiğini bildirmişlerdir. Çalışmalar arasındaki farklılıklar kullanılan genotiplerin ve ekim sıklıklarının farklı olmasından kaynaklanmaktadır. Nitekim, Steberl ve ark. [9], çiçek değiștiğini bildirmişlerdir. Bu çalıșmada çiçek veriminin yüksek ve varyasyonun daha fazla olmasının nedeni olarak; kullanılan genotip sayısının fazla olması ve sira arası mesafenin $20 \mathrm{~cm}$ olması sebebiyle metrekaredeki bitki sayısının diğer çalışmalardan daha yüksek olması söylenebilir. 
Tablo 3. Araştırmada incelenen çiçek verimi ve diğer özelliklere ait ortalama değerler

\begin{tabular}{|c|c|c|c|c|c|c|c|}
\hline Genotip & Hat No & Çiçek Rengi & ÇV & TÇ & TS & YDS & BB \\
\hline G1 & $63-2-b$ & Sar1- Turuncu & $24,0 \mathrm{a}$ & 2,33 cde & $13,0 \mathrm{bc}$ & $11,0 \mathrm{bc}$ & 60,7 e-1 \\
\hline Göktürk & Göktürk & Sar1-Turuncu & $22,2 \mathrm{ab}$ & $2,13 \mathrm{ijk}$ & $8,5 \mathrm{~d}-\mathrm{h}$ & $7,5 \mathrm{f}-1$ & $58,5 \mathrm{gh} 1$ \\
\hline Linas & Linas & Sar1-Turuncu & $21,5 \mathrm{ab}$ & $2,23 \mathrm{e}-1$ & $14,5 \mathrm{ab}$ & $12,5 \mathrm{ab}$ & $70,7 \mathrm{a}$ \\
\hline G2 & $56-2-c$ & Sarı & $20,7 \mathrm{abc}$ & $2,28 \mathrm{~d}-\mathrm{g}$ & $10,5 \mathrm{~cd}$ & 8,0 e-h & $68,5 \mathrm{ab}$ \\
\hline G3 & $25-3-a$ & Sar1-Turuncu & 20,0 a-d & $2,05 \mathrm{k}$ & $15,0 \mathrm{ab}$ & $13,0 \mathrm{a}$ & 67,0 a-d \\
\hline G4 & $77-1-d$ & Turuncu & 20,0 a-d & $2,18 \mathrm{~g}-\mathrm{j}$ & $10,5 \mathrm{~cd}$ & $8,5 \mathrm{efg}$ & $63,5 \mathrm{c}-\mathrm{f}$ \\
\hline Dinçer & Dinçer & Kırmızı & $18,7 \mathrm{bcd}$ & $2,21 \mathrm{f}-1$ & $11.0 \mathrm{~cd}$ & $6,7 \mathrm{gh} 1$ & $67,5 \mathrm{abc}$ \\
\hline G5 & $107-2-a$ & Beyaz & $18,0 \mathrm{~b}-\mathrm{e}$ & $2,31 \mathrm{c}-\mathrm{f}$ & $10,0 \mathrm{de}$ & $8,2 \mathrm{e}-\mathrm{h}$ & 57,51 \\
\hline G6 & $83-1-a$ & Kırmızı & $18,0 \mathrm{~b}-\mathrm{e}$ & $2,10 \mathrm{jk}$ & $9,2 \mathrm{~d}-\mathrm{g}$ & $8,5 \mathrm{efg}$ & $65,0 \mathrm{~b}-\mathrm{e}$ \\
\hline G7 & $96-3$ & Sarı & $18,0 \mathrm{~b}-\mathrm{e}$ & $2,21 \mathrm{f}-1$ & 9,7 def & $10,5 \mathrm{~cd}$ & $61,0 \mathrm{e}-1$ \\
\hline G8 & $42-b$ & Sarı & $17,7 \mathrm{~b}-\mathrm{e}$ & $2,48 \mathrm{ab}$ & $11,0 \mathrm{~cd}$ & $9,2 \mathrm{c}-\mathrm{f}$ & $59,2 \mathrm{f}-1$ \\
\hline G9 & $11-1$ & Sar1-Turuncu & 16,5 cde & $2,37 \mathrm{bcd}$ & 8,7 d-h & $11,0 \mathrm{bc}$ & $61,5 \mathrm{e}-1$ \\
\hline G10 & $79-4$ & Turuncu & 16,2 cde & $2,17 \mathrm{hij}$ & $16,5 \mathrm{a}$ & $13,2 \mathrm{a}$ & $71,5 \mathrm{a}$ \\
\hline G11 & $2010-9$ & Turuncu & $16,0 \mathrm{def}$ & $2,28 \mathrm{~d}-\mathrm{g}$ & $9,0 \mathrm{~d}-\mathrm{h}$ & $7,5 \mathrm{f}-1$ & $62,5 \mathrm{~d}-\mathrm{h}$ \\
\hline G12 & $28-2$ & Sar1-Turuncu & $15,5 \mathrm{def}$ & $2,57 \mathrm{a}$ & $11,2 \mathrm{~cd}$ & $9,0 \mathrm{def}$ & $63,0 \mathrm{c}-\mathrm{g}$ \\
\hline G13 & $106-2$ & Sarı & 14,0 ef & $2,40 \mathrm{bc}$ & 7,5 e-h & 9,5 cde & 58,0 hi \\
\hline Balc1 & Balc1 & Sar1 & 13,5 ef & $2,17 \mathrm{hij}$ & $7,0 \mathrm{fgh}$ & $6,0_{1}$ & $61,5 \mathrm{e}-1$ \\
\hline G14 & $82-3$ & Sar1 & $11,5 \mathrm{fg}$ & $2,20 \mathrm{~g}-\mathrm{j}$ & $6,2 \mathrm{~h}$ & $7,5 \mathrm{f}-1$ & $61,2 \mathrm{e}-1$ \\
\hline Koç & Koç & Sarı & $11,5 \mathrm{fg}$ & $2.26 \mathrm{e}-\mathrm{h}$ & $6,7 \mathrm{gh}$ & 6,5 h1 & $60,5 \mathrm{e}-1$ \\
\hline \multirow[t]{4}{*}{ G15 } & $13-2-c$ & Sar1-Turuncu & $8,5 \mathrm{~g}$ & $2,13 \mathrm{ijk}$ & $6,5 \mathrm{gh}$ & $6,5 \mathrm{~h} 1$ & 67,0 a-d \\
\hline & & Ortalama & 17,1 & 2,2 & 10,0 & 9,0 & 63,3 \\
\hline & & LSD & 4,7 & 0,1 & 2,9 & 1,8 & 4,6 \\
\hline & & VK $(\%)$ & 17,6 & 3,1 & 20,0 & 14,1 & 5,2 \\
\hline
\end{tabular}

ÇV: Çiçek Verimi (kg/da), TÇ: Tabla Çapı (cm), TS: Tabla Sayısı (adet), YDS: Yan Dal Sayısı (adet), BB: Bitki Boyu (cm)

Tabla çapı değerleri ise 2,10 $\mathrm{cm}$ ile $2,57 \mathrm{~cm}$ arasında değişmiş olup deneme ortalaması $2,20 \mathrm{~cm}$ bulunmuştur. Bitki başına ortalama tabla sayısı 6,2 - 16,5adet arasında değişmiş, ortalama tabla sayısı 10,0 adet olmuştur. Yan dal sayısı 6,0 $-13,2$ adet arasında değişmiş deneme ortalaması 9,0 adet olarak belirlenmiştir. Yapılan ölçümlerden bitki boyu değerleri ise $57,5 \mathrm{~cm}$ ile $71,5 \mathrm{~cm}$ arasında değişmiş, ortalama $63,3 \mathrm{~cm}$ olarak tespit edilmiştir (Tablo 3).

Tablo 4.Çiçek verimi ve bazı morfolojik özellikler arasında tespit edilen korelasyon katsayıları

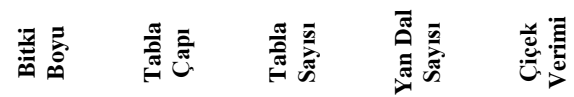

\begin{tabular}{|c|c|c|c|c|c|}
\hline $\begin{array}{l}\text { Bitki Boyu } \\
\text { Tabla }\end{array}$ & 1,00 & & & & \\
\hline $\begin{array}{l}\text { Çapı } \\
\text { Tabla }\end{array}$ & $-0,25^{*}$ & 1,00 & & & \\
\hline $\begin{array}{l}\text { Sayısı } \\
\text { Yan Dal }\end{array}$ & $0,28 *$ & 0,01 & 1,00 & & \\
\hline $\begin{array}{l}\text { Sayısı } \\
\text { Çiçek }\end{array}$ & 0,17 & 0,04 & $0,81 * *$ & 1,00 & \\
\hline Verimi & 0,02 & $-0,05$ & $0,40 * *$ & $0,33 * *$ & 1.00 \\
\hline
\end{tabular}

Çiçek verimi ve bazı morfolojik özellikler arasında korelasyon analizi incelendiğinde (Tablo 4); çiçek verimi ile tabla sayısı ve yan dal sayısı arasında pozitif ve önemli korelasyon bulunmuştur. Buna karşıllk çiçek verimi ile bitki boyu ve tabla çapı arasında ilişkinin önemsiz olduğu tespit edilmiştir. Steberl ve ark.[9] tabla ağırlığı ile çiçek verimi arasında pozitif ilişki olduğunu bildirmişlerdir. Bitki başına tabla ağırlığı dolayısıyla tabla sayısı fazla olduğu zaman çiçek veriminin fazla olması beklenen bir sonuçtur. Fazla sayıda dallanan ve tabla oluşturan genotiplerin çiçek verimleri de yüksek olmuştur.

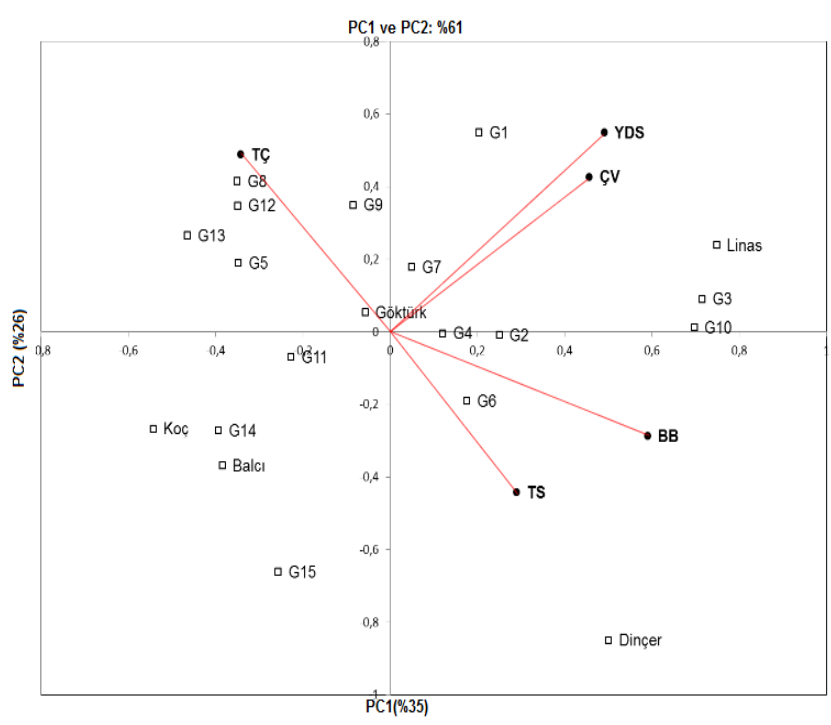

Şekil 3. Aspir genotipleri için çiçek verimi ve bazı morfolojik özelliklere ait Genotip- özellik ve özellikler arasındaki ilişkiyi gösteren biplot grafiği. Özellikler: ÇV: Çiçek Verimi, TÇ: Tabla Çapı, TS: Tabla Sayısı, YDS: Yan Dal Sayısı, BB: Bitki Boyu.

Araştırmada Genotip-Özellik bakımından GT Biplot grafiği incelendiğinde; toplam varyasyonu temsil oranını veren; PC1 (Ana bileşen1) \% 35 ve PC2 (Ana bileşen2) $\% 26$ değerleri toplamının \% 61 olduğu görülmektedir. (Şekil 3). \% PC1 ve \% PC2 değerleri toplamının yüksek olması GGE biplot grafiklerinde istenilen bir durumdur. $\mathrm{Bu}$ değer yüksek olduğunda araştırıcıların daha güvenli bir şekilde yorum yapabileceği Yan ve ark. [25] tarafindan bildirilmektedir.

Biplot grafiğinin toplam varyasyonu yeterli miktarda açıklaması için toplam ana bileşen oranının \% 50'den daha büyük olması gerekir [26]. Bu çalışmada bu değer \% 61 olmuştur. İki özellik vektörleri arasındaki açı $<90^{\circ}$ ise korelasyon katsayısı pozitif, eğer açı $>90^{\circ}$, ise korelasyon katsayısı(r) negatif değer, açı $=90^{\circ}$ ise 
korelasyon katsayısı 0 bağımsız olarak değerlendirilir [27,28]. Biplot grafiği incelendiğinde Çiçek verimi (ÇV) ile Yan dal sayısı (YDS) ve Tabla sayısı (TS) arasındaki açının $90^{\circ}$ den küçük olduğu görünmektedir. Dolayısıyla Biplot grafiğine göre çiçek verimi ile yan dal sayısı ve tabla sayısı arasında pozitif ilişki vardır.

Biplot grafiğinde gözlenen sonuçlar (Şekil 3) ile korelasyon tablosu (Tablo 4) sonuçları büyük ölçüde birbirini desteklemektedir. Biplot grafiğini GenotipÖzellik ilişkileri açısından incelediğimizde çiçek verimi (ÇV) bakımından hatlardan G1, G2, G3, G4, G5, G6 ve G7 ön plana çıkarken, tescilli çeşitlerden Göktürk ve Linas çeşitleri daha yüksek çiçek verimi performansı göstermiştir. Çiçek verimi bakımından ortalamanın altında verim veren hat ve çeşitler ise G15, Koç, G14, Balcı genotipleri olmuştur.

\section{SONUÇ}

Aspirde çiçek verimi açısından tescilli çeşitlerden Göktürk ve Linas, hatlardan G1, G2 ve G3 genotiplerinin önemli potansiyelleri mevcuttur. Genotipler arasında çiçek verimi açısından önemli varyasyon vardır. Aspir çiftçisinin gelirini artırma açısından tohumu yanında diğer önemli bir kullanım alanı olan doğal boya endüstrisi için çiçeğinden faydalanılması aspir yetiştiricilerinin gelirini artıracak ve bu bitkinin ekiminin yaygınlaşmasına katkı sağlayacaktır.

$\mathrm{Bu}$ çalışma, aspirde çiçek verimi ile bazı morfolojik özellikler arasındaki ilişkileri hem korelasyon analizi hem de biplot analizi ile ortaya koyma bakımından önemlidir. Araştırma sonucunda her iki analize göre de çiçek verimi ile tabla sayısı ve yan dal sayısı arasında önemli ve pozitif ilişki tespit edilmiştir. Genotip- Özellik Biplot grafiği sayesinde genotiplerin özellikler yönünden kuvvetli ve zayıf yönlerini pratik bir şekilde inceleme ve değerlendirme imkânı olmuştur.

Türkiye'de aspirin tohumunun çiçeğiyle hasat edilerek daha sonra harmanla çiçeğinin değerlendirilmesi üzerine mekanizasyon çalışmalarının bulunmaması önemli bir eksikliktir. Bu çalışmada olduğu gibi çiçeklerin elle toplanarak çiçek veriminin elde edilmesi, genotiplerin çiçek verim potansiyellerini belirleme açısından önemli olmakla birlikte pratikte, makinalı hasada yönelik çalışmaların olması gerekmektedir. Aspir çiçeği üzerine yapılan çalıșmaların birçoğunda çiçekler, tam çiçek zamanında toplanırken, bu çalışmada hasada yakın zamanda toplanmış bu bakımdan da elde edilen veriler pratiğe daha uygun olmuştur. Çünkü aspir çiçeğinin hasadı, tohum için hasadıyla beraber değerlendirilmesi gereken bir husustur. Türkiye'de önemli bir ekim potansiyeline sahip olan aspir bitkisinin çiçeğinin hem boya olarak, hem de tıbbi amaçlı kullanımına yönelik çalışmalar yapılmalıdır.

\section{KAYNAKLAR}

[1] Emongor V, Oagile O. Safflower production. Impression house publication. Gaborone. Botswana; 2017.
[2] Emongor V. Safflower (Carthamus tinctorius L.) the underutilized and neglected crop: a review. Asian Journal of Plant Sciences. 2010; 9(6):299306.

[3] Garfield S. Mauve. How one man invented a color that changed the world. WW Norton and Company: New York. NY; 2002.

[4] Velasco L, Fernandez-Martinez JM. Progress in breeding for modified tocopherol content and composition in safflower. Sesame and Safflower Newsletter. 2002(17):98-102.

[5] Ekin Z. Resurgence of safflower (Carthamus tinctorius L.) utilization: A global view. Journal of Agronomy. 2005; 4(2):83-7.

[6] Nagaraj G, Devi GN, Srinivas CVS. Safflower petals and their chemical composition. proc. V. International Safflower Conference, USA; 2001. P.123-27.

[7] Dajue L, Mündel HH. Safflower (Carthamus tinctorius L.). IPGRI. IPK. Eds.: IPGRI: Rome, Italy; 1996.

[8] Baydar H. Gibberellik asidin aspir (Carthamus tinctorius L.)'de erkek kısırlık, tohum verimi ile yağ ve yağ asitleri sentezi üzerine etkisi. Tr. J. Biology. 2000; 24: 159-168.

[9] Steberl K, Hartung J, Graeff-Hönninger S. Impact of cultivar, harvest date and threshing parameter settings on floret and Carthamidin yield of safflower. Agronomy. 2020; 10(9):1272.

[10] Gao WY, Fan L, Paek KY. Yellow and red pigment production by cell cultures of Carthamus tinctorius in a bioreactor. Plant cell, tissue and organ culture. 2000; 60(2):95-100.

[11] Kumar JK, Sinha AK. Resurgence of natural colorants: a holistic view. Natural product research. 2004; 18(1):59-84.

[12] Arnold LE, Lofthouse N, Hurt E. Artificial food colors and attention-deficit/hyperactivity symptoms: conclusions to die for. Neurotherapeutics. 2012; 9(3):599-609.

[13] Krizova H. Natural dyes: their past, present, future and sustainability. Recent Developments in Fibrous Material Science. Prague: Kosmas Publishing. 2015.

[14] Yoon JM, Cho MH, Park JE, Kim YH, Hahn TR, Paik YS. Thermal stability of the pigments hydroxysa safflower yellow A, safflower yellow B, and precarthamin from safflower (Carthamus tinctorius). Journal of food science. 2003; 68(3):839-43.

[15] Shin YS, Yoo DI. Storage Stability and Color Reproducibility of Yellow and Red Dyes Extracted from Carthamus tinctorius L. Textile Coloration and Finishing. 2012; 24(3):165-72

[16] Azimi S, Chegini G, Kianmehr MH. Design and manufacture of safflower petal harvester machine. Mechanics \& Industry. 2012; 13(5):301-5.

[17] Mc Guire PE, Damania AB, Qualset CO. Safflower in California. The Paulden F. Knowles personal history of plant exploration and research on evolution, genetics, and breeding. Agronomy Progress report. No. 313. Dept. of Plant Sciences. 
University of California. Davis CA. USA; 2012. p. $1-44$.

[18] Yun G, Lixin Z, Ying Q, Xiaopan J, Yuanbo C. Dynamic model for sucking process of pneumatic cutting-type safflower harvest device. International Journal of Agricultural and Biological Engineering. 2016; 9(5):43-50.

[19] Zimmer S, Müller Literatursammlung und auswertung zur Erntetechnologie von arznei- und Gewürzpflanzen: Schlussbericht zum Vorhaben. Laufzeit; 2002.

[20] Anonim. 2020. Türkiye İstatistik Kurumu, https://data.tuik.gov.tr/ 16.03.2021.

[21] Köse A, Bilir Ö. Aspir bitkisinde (Carthamus tinctorius L.) farklı sıra arası mesafelerin ve ekim normunun taç yaprak verimi ve bazı bitkisel özellikler üzerine etkisi. Türk Tarım ve Doğa Bilimleri Dergisi. 2017;4(1):40-7.

[22] Süer İE. Bazı Aspir (Carthamus tinctorius L.) çeşitlerinde farklı gelişme dönemlerinde yapılan sulamaların verim ve bazı agronomik özellikler üzerine etkisi. Çukurova Ü. Fen Bil. Ens. Tarla Bitkileri ABD Yüksek Lisans Tezi; 2011.

[23] Uysal N, Baydar H, Erbaş S. Isparta popülasyonundan geliştirilen aspir (Carthamus tinctorius L.) hatlarının tarımsal ve teknolojik özelliklerinin belirlenmesi. Ziraat Fakültesi Dergisi. 2006;1(1):52-63.

[24] Kırıcı S, İnan M. Aspirde (Carthamus tinctorius L.) farklı sıra aralıklarının verim komponentleri ile çiçek verimine ve boyar madde oranına etkileri. ÇÜ. Ziraat Fakültesi Dergisi. 2005;20 (2): 117-124.

[25] Yan W, Kang MS, Ma B, Woods S, Cornelius PL. GGE biplot vs. AMMI analysis of genotype-byenvironment data. Crop science. 2007 Mar; 47(2):643-53.

[26] Kroonenberg PM.Introduction to biplot for $G \times E$ tables. Department of Mathematics. Research Report5. 2016. Available from: http://threemode.leidenuniv.nl/document/biplot.pdf.

[27] Yan W, Hunt LA. Interpretation of genotype $\times$ environment interaction for winter wheat yield in Ontario. Crop Science. 2001; 41(1):19-25.

[28] Rad MN, Kadir MA, Rafii MY, Jaafar HZ, Naghavi MR, Ahmadi F. Genotype environment interaction by AMMI and GGE biplot analysis in three consecutive generations of wheat (Triticum aestivum) under normal and drought stress conditions. Australian Journal of Crop Science. 2013; 7(7):956-996. 